\title{
Insect chemoreception: a tribute to John G. Hildebrand
}

\author{
Wolfgang Rössler $\cdot$ Monika Stengl
}

Received: 17 September 2013 / Accepted: 19 September 2013 / Published online: 10 October 2013

(C) Springer-Verlag Berlin Heidelberg 2013

This special issue is dedicated to John G. Hildebrand, Regents Professor, founding director and many years (1985-2013) head of the Arizona Research Laboratories Division of Neurobiology (since 2009 the Department of Neuroscience), University of Arizona in Tucson, to pay tribute to his outstanding contributions over his long career devoted to understanding the neuroethology of insect chemoreception.

Chemosensory systems play key roles for the survival and reproduction of most animal species. It has puzzled scientists since many years how the highly complex molecular olfactory world is detected by olfactory receptors, encoded into neuronal activity, and processed within the central nervous system to finally trigger adaptive behavior. Even today, olfactory transduction as well as encoding and perception are far from being understood and are lively debated in the various areas of chemosensory research. Since the beginning, insects have played a very influential role in this field, due to the important role of olfaction for insect behavior and the accessibility of insects for different experimental manipulations.

Insect model systems allow integrative analyses at all levels of complexity: from molecular genetics and identified single-cell studies to the analysis of neuronal networks and the examination of insect behavior in interaction with its ecological niche (for recent reviews Galizia and Rössler

W. Rössler $(\bowtie)$

Behavioral Physiology and Sociobiology (Zoology II), Biozentrum, University of Würzburg, Am Hubland, 97074 Würzburg, Germany

e-mail: roessler@biozentrum.uni-wuerzburg.de

M. Stengl

FB 10, Biology, Animal Physiology, University of Kassel, Heinrich Plett Str. 40, 34132 Kassel, Germany
2010; Hansson and Stensmyr 2011; Martin et al. 2011). Especially, research on sex-pheromone systems in Lepidoptera has significantly contributed to the understanding of the functional organization and physiology of the insect olfactory system (Hildebrand 1996). The pioneering studies on moths were followed by research on other insect chemosensory model systems, which boosted the whole field of chemosensory sciences. Social Hymenoptera like the honeybee and ants have opened up the field for the study of mechanisms of chemosensory behavior in the context of social communication, learning and memory (e.g. Hölldobler 1999; Menzel and Giurfa 2001; Galizia and Rössler 2010). The astounding genetic tool-box of Drosophila melanogaster allowed for the rise of neurogenetics that dissected chemosensory behavior all the way down to the level of behaviorally relevant genes (e.g. Konopka and Benzer 1971; Fernández and Kravitz 2013, in this issue). Due to the enormous breadth of experimental approaches that can be applied, chemosensory research on insects today represents a most lively, original, stimulating, and innovative field in the behavioral neurosciences with a close link to chemical and behavioral ecology. On one hand, it demonstrates common principles of chemosensory systems even shared between insects and mammals (e.g. Hildebrand and Shepherd 1997), and on the other hand, it illustrates the amazingly inventive variations to common schemes across different species adapted to various environments (Galizia and Rössler 2010; Hansson and Stensmyr 2011).

This special issue is based upon the topics of an international symposium at the University of Würzburg, Germany, in July 2012, in honor of John Hildebrand. The symposium was initiated by Ed Kravitz and Monika Stengl and was organized by Wolfgang Rössler (University Würzburg, Germany) and Monika Stengl (University of Kassel, Germany). The meeting was supported by the DFG priority 
program 'Integrative analysis of olfaction'. Thus, this special issue expands on the three themes of the Würzburg symposium: (1) peripheral reception, (2) olfactory processing in the antennal lobe and higher brain centers, and (3) odor-dependent behavior.

The first section starts at the peripheral level with two reviews highlighting two topics of odor transduction. A model of odor transduction kinetics attributes the kinetics of olfactory sensory neurons largely to odorant-receptor interactions and to odorant deactivation by odorant binding proteins (Kaissling 2013). A review on the role of the conserved coreceptor Orco discusses ionotropic versus metabotropic odor transduction cascades for insects (Stengl and Funk 2013). Both contributions suggest new hypotheses and state that in particular the transduction cascades are far from being completely understood and, as a consequence, are under lively debate.

The second section concentrates on olfactory processing in antennal lobe (AL) glomeruli, the neuronal processing units in the first olfactory relay station, and on AL output to higher olfactory brain centers. This section starts with a review providing a comparative perspective on odorant processing and mixture coding in insect olfactory systems (Clifford and Riffell 2013). The contribution by Heinbockel et al. (2013) reviews glomerular interactions in the $\mathrm{AL}$ of Manduca sexta, in particular in pheromone-specific and plant-odor responsive AL neurons (see also Martin and Hildebrand 2010). Rein et al. (2013) present new results on octopaminergic modulatory influences at the level of AL glomeruli using calcium imaging of glomerular activation patterns in honeybees. The importance of temporal aspects in coding behaviorally relevant odorant mixtures is demonstrated by Martin et al. (2013) using multi-unit electrophysiological recordings of AL neurons and behaviorally relevant mixtures of sex-pheromone components in Manudca sexta. The contribution by Rössler and Brill (2013) focuses on neurophysiological, anatomical and evolutionary aspects of parallel processing of olfactory information along the olfactory pathway, in particular using simultaneous multi-unit recordings from two sets of $\mathrm{AL}$ projection neurons within a dual olfactory pathway in the honeybee (Brill et al. 2013). The contribution by Lei et al. (2013) concludes this section by presenting new results on processing of sex-pheromone information by protocerebral neurons in Manduca sexta.

The third section on odor-dependent behavior starts with a research contribution by Willis and Ford (2013) on mechanisms of odor-tracking behavior of male Manduca sexta along pheromone plumes of variable sizes. Kanzaki et al. (2013) reviews the use and benefit of insectmachine hybrid systems to promote our understanding of sensory-motor control of pheromone tracking behavior. The contribution by Contreras et al. (2013) asks how floral preferences in Manduca sexta are modulated or prioritized by environmental conditions, in particular humidity. The section on chemosensory behavior concludes with a review by Fernández and Kravitz (2013) on the influences of pheromones and chemical cues on aggression and courtship behavior and their genetic basis in the fruit fly Drosophila melanogaster.

We dedicate this special issue to John G. Hildebrand to pay tribute to his many years of excellent research and his influential role as the founding director and head of the Arizona Research Laboratories Division of Neurobiology at the University of Tucson, which, as a central part of the Center for Insect Sciences in Tucson, became "the Mekka" for scientists from all over the world working on the neurobiology of insect behavior, not only in the field of olfaction. John devoted his long and highly productive career to understanding multiple aspects of insect chemical communication, olfactory physiology, development and behavior using the giant sphinx moth, Manduca sexta, as a favorable and very successful model system (Hildebrand 1996; Martin et al. 2011).

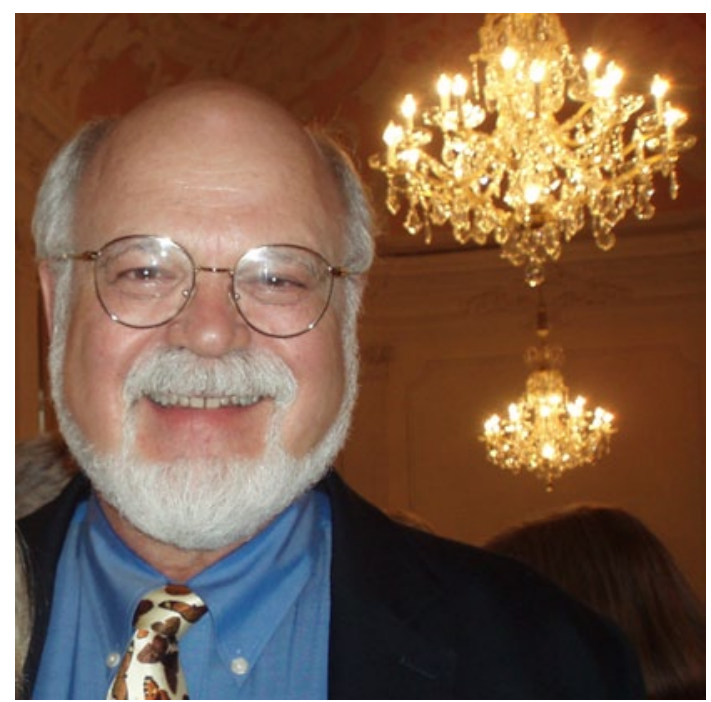

John G. Hildebrand at the international symposium 'Olfaction in insects under debate: from receptors to behaviors' that took place in Würzburg, Germany on 20 July 2012 (private photo)

John Hildebrand was born in 1942 in Boston, Massachusetts. He graduated at Harvard University in 1964 (mentors: John Law and Konrad Bloch), received his Ph.D. in biochemistry at Rockefeller University in 1969 (mentors: Leonard Spector and Fritz Lipmann), and was a postdoctoral fellow with Edward Kravitz at the Department of Neurobiology, Harvard Medical School. From 1970 to 1980 John was a faculty member at the Department of Neurobiology at Harvard Medical School. Then, from 1980 to 1985, he was Professor of Biological Sciences at Columbia 
University and (1981-1986) Adjunct Professor at Rockefeller University. In 1985 he moved to the University of Arizona as founding director of the Arizona Research Laboratories Division of Neurobiology. John received numerous awards and prizes, the latest being the AChemS Max Mozell Award for Outstanding Achievements in the Chemical Sciences, his nomination as Fellow of the International Society for Neuroethology and as Honorary Fellow of the Royal Entomological Society of London. John's exceptional influences in the field of insect chemosensory systems are not only apparent from the many excellent publications that came out of his laboratory, but also by the fact that many of nowadays established scientists in the field of insect behavioral neurosciences had spent important years in John's lab in Tucson. With this special issue we pay tribute to John Hildebrand and his outstanding achievements as researcher and mentor in the field of insect chemosensory systems and neuroethology.

To honor John Hildebrand's contributions to the field of insect chemosensory systems and to celebrate his 70th birthday the symposium "Olfaction in insects under debate" was dedicated to him. It took place on 20 July 2012 in the "Toscana-Saal" of the famous Residency Palace in Würzburg, Germany with 100 participants from all over the world. The symposium was a great success as it provided new insights, stimulated many lively discussions, and triggered new scientific cooperation. This special issue summarizes key findings reported at the meeting and, thus, highlights important new findings and unsolved questions in the exciting field of insect olfaction.

Acknowledgments We thank the German Research Foundation (DFG Priority Program, SPP 1392 'Integrative analysis of olfaction'; and SFB 554) and the University of Würzburg for supporting the international symposium that preceded this special issue.

\section{References}

Brill MF, Rosenbaum T, Reus I, Kleineidam CJ, Nawrot MP, Rössler W (2013) Parallel processing via a dual olfactory pathway in the honeybee. J Neurosci 33:2443-2456

Clifford MR, Riffell JA (2013) Mixture and odorant processing in the olfactory systems of insects: a comparative perspective. J Comp Physiol A (in this issue). doi:10.1007/s00359-013-0818-6

Contreras HL, Goyret J, von Arx M, Pierce CT, Bronstein JL, Raguso RA, Davidowitz G (2013) The effect of ambient humidity on the foraging behavior of the hawkmoth Manduca sexta. J Comp Physiol A (in this issue). doi:10.1007/s00359-013-0829-3
Fernández MP, Kravitz EA (2013) Aggression and courtship in Drosophila: pheromonal communication and sex recognition. J Comp Physiol A (in this issue). doi:10.1007/s00359-013-0851-5

Galizia CG, Rössler W (2010) Parallel olfactory systems in insects: anatomy and function. Annu Rev Entomol 55:399-420

Hansson B, Stensmyr MC (2011) Evolution of insect olfaction. Neuron 72:698-711

Heinbockel T, Shields VDC, Reisenmann CE (2013) Glomerular interactions in olfactory processing channels of the antennal lobes. $\mathrm{J}$ Comp Physiol A (in this issue). doi:10.1007/s00359-013-0842-6

Hildebrand JG (1996) King Solomon lecture-olfactory control of behavior in moths: central processing of odor information and the functional significance of olfactory glomeruli. J Comp Physiol A 178:5-19

Hildebrand JG, Shepherd GM (1997) Mechanisms of olfactory discrimination: converging evidence for common principles across phyla. Annu Rev Neurosci 20:595-631

Hölldobler B (1999) Multimodal signals in ant communication. J Comp Physol A 184:129-141

Kaissling K-E (2013) Kinetics of olfactory responses might largely depend on the odorant-receptor interaction and the odorant deactivation postulated for flux detectors. J Comp Physiol A (in this issue). doi:10.1007/s00359-013-0812-Z

Kanzaki R, Minegishi R, Namiki S, Ando N (2013) Insect-machine hybrid system for understanding and evaluating sensory-motor control by sex pheromone in Bombyx mori. J Comp Physiol A (in this issue). doi: 10.1007/s00359-013-0832-8

Konopka RJ, Benzer S (1971) Clock mutants of Drosophila melanogaster. PNAS 68:2112-2116

Lei H, Chiu HY, Hildebrand JG (2013) Responses of protocerebral neurons in Manduca sexta to sex-pheromone mixtures. J Comp Physiol A (in this issue). doi:10.1007/s00359-013-0844-4

Martin JP, Hildebrand JG (2010) Innate recognition of pheromone and food odors in moths: a common mechanism in the antennal lobe? Front Behav Neurosci 4:159

Martin JP, Beyerlein A, Dacks AM, Reisenman CE, Riffel JA, Lei H, Hildebrand JG (2011) The neurobiology of insect olfaction: sensory processing in a comparative context. Prog Neurobiol 95:427-447

Martin JP, Lei H, Riffell JA, Hildbrand JG (2013) Synchronous firing of antennal-lobe projection neurons encodes the behaviorally effective ratio of sex-pheromone components in male Manduca sexta. J Comp Physiol A (in this issue). doi:10.1007/ s00359-013-0849-Z

Menzel R, Giurfa M (2001) Cognitive architecture of a mini-brain: the honeybee. Trends Cogn Sci 5:62-71

Rein J, Musard JA, Strauch M, Smith BH, Galizia CG (2013) Octopamine modulates activity of neural networks in the honey bee antennal lobe. J Comp Physiol A (in this issue). doi:10.1007/ s00359-013-0805-y

Rössler W, Brill MF (2013) Parallel processing in the honeybee olfactory pathway: structure, function, and evolution. J Comp Physiol A (in this issue). doi:10.1007/s00359-013-0821-y

Stengl M, Funk NW (2013) The role of the coreceptor Orco in insect olfactory transduction. J Comp Physiol A (in this issue). doi:10.1007/s00359-013-0837-3

Willis M, Ford E (2013) Odor tracking flight of male moths, Manduca sexta, along plumes of different cross-sectional area. J Comp Physiol A (in this issue). doi:10.1007/s00359-013-0856-0 